\title{
ARTHROSCOPIC RELEASE OF THE SUPRASCAPULAR NERVE: SURGICAL TECHNIQUE AND EVALUATION OF CLINICAL CASES
}

José Carlos Garcia Júnior ${ }^{1}$, Ana Maria Ferreira Paccola², Cristiane Tonoli², José Luis Amin Zabeu ${ }^{3}$, Jesely Pereira Myrrha Garcia ${ }^{4}$

\section{ABSTRACT}

Objective: To describe a specific surgical technique for arthroscopic decompression of the suprascapular nerve (SSN) and evaluate its preliminary results. Methods: Ten shoulders of nine patients were operated using a technique with portals differing from the already-known techniques, which did not use traction and made use of materials available within the public healthcare system. Results: Among the ten shoulders of nine patients, eight were right shoulders and two were left shoulders. The mean age was 69.5 years. The UCLA score increased from 11.7 to 26.1 points over the postoperative follow-up of 16.6 months. The SF36 questionnaire score was 122.9 and the raw pain scale value was $88 \%$. Conclusion: Arthroscopic decompression of the SSN in accordance with the described technique is reproducible and less traumatic than the open techniques. The patients achieved improvements in many of the parameters evaluated, particularly with regard to pain. Arthroscopic decompression of the SSN may be a therapeutic option for pathological compression of the SSN.

Keywords - Nerve Crush; Decompression, Surgical; Shoulder Pain; Arthroscopy/methods; Shoulder

\section{INTRODUCTION}

The suprascapular nerve (SSN) is responsible for motor innervation of the supraspinatus and infraspinatus muscles and for sensory innervation of the glenohumeral joint. It passes through the scapular incisure and may become trapped and compressed against the transverse ligament of the scapula, in an elastic compressive mechanism, according to Thompson and Kopell ${ }^{(1)}$.

Compression of the SSN may have various causes, including anomalies of the transverse ligament of the scapula, compression due to paralabral cysts, abnormal bone morphology of the scapular incisure, lesions due to traction, repetitive or exaggerated movements of the shoulder, rotator cuff tears and trauma. Idiopathic compression of the $\mathrm{SSN}$ is a relatively rare phenomenon that is possibly underdiagnosed. The most common causes of pinching of the SSN are massive injuries to the rotator cuff and extreme tension secondary to rotator cuff repairs. Massive injuries may retract, thereby compressing the SSN against the transverse ligament of the scapula. In such cases, decompression of the nerve at the scapular incisure is recommended ${ }^{(2)}$.

According to Mallon et $\mathrm{al}^{(3)}$, neuropathy of the SSN may be associated with massive injuries of the rotator cuff, and partial reconstruction of the cuff promotes recovery of the nerve and functional improvement.

The diagnosis may be difficult and should be put forward in situations of pain associated with loss of strength to perform lateral rotation of the shoulder,

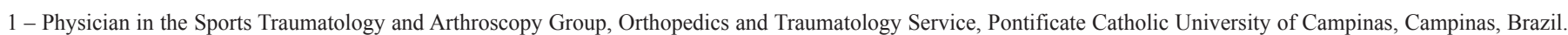

2 - Physician and third-year Orthopedics Resident in the Department of Orthopedics and Traumatology, Pontificate Catholic University of Campinas, Campinas, Brazil.

3 - Head of the Department of Orthopedics and Traumatology, Pontificate Catholic University of Campinas, Campinas, Brazil.

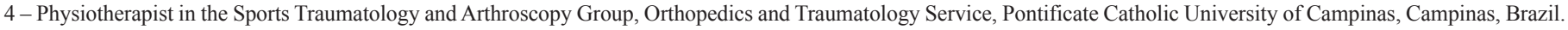

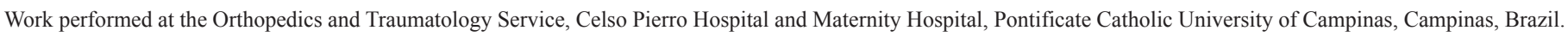
Correspondence: Rua Indiana, 670 - 04562-001 - São Paulo, SP, Brasil. E-mail: josecarlos@especialistadoombro.com.br

Work received for publication: June 14, 2010; accepted for publication: September 24, 2010.

The authors declare that there was no conflict of interest in conducting this work 
with the infraspinatus muscle intact ${ }^{(4)}$. If the condition is chronic, the compression may cause fat degeneration and muscle atrophy. Electroneuromyography is the preferred examination for aiding in the diagnostic investigation, although it is not easy to perform and its results are often questionable.

Release of the superior transverse ligament of the scapula has been suggested as a therapeutic option with demonstrable pain relief and functional improvement. Surgical release of the nerve is indicated for patients with chronic shoulder pain and electroneuromyographic evidence of SSN compression; for cases of massive painful and irreparable injury of the rotator cuff (with retraction greater than $5 \mathrm{~cm}$ ); and for cases with sutures of the supraspinatus under great tension. There are surgical options with an open approach and via arthroscopy. Open surgery involves a non-esthetic extensive incision, and viewing the nerve is difficult. Both posterior and superior approaches towards open-surgery release of the SSN have been described $^{(4,5)}$. Another negative point relating to open surgery is the need for deinsertion of the trapezius muscle along the spine of the scapula, since muscle weakness may occur after the operation, with dropped shoulders. There is currently a trend towards preferring arthroscopic procedures in general, since they are minimally invasive, cause less muscle injury, are faster and lead to early postoperative rehabilitation.

The aims of this study were to describe a technique for arthroscopic decompression of the SSN that is less traumatic for patients and to evaluate its preliminary results.

\section{MATERIALS}

In this prospective study, nine patients with irreparable injuries of the rotator cuff associated with mild or moderate glenohumeral arthropathy were operated and evaluated. All of them presented severe pain, and one had bilateral compression.

Since these were all irreparable injuries, no reconstruction of the unviable tendons was performed in any case, given the severe fatty degeneration of the tendons. In all cases, the degree of filling of the "Y" of the lower scapula was less than $50 \%$. The patients were selected by means of specific physical examinations, electroneuromyography on the affected shoulder and assessment using specific scales: UCLA score (University of California at Los Angeles) and the raw scale of pain before the operation. Six months after the operation, the UCLA score ${ }^{(6)}$, SF-36 $6^{(7)}$ (Short Form Health Survey) and raw scale of pain ${ }^{(8)}$ were used. The UCLA score is a specific graded scale for the shoulder that is used as a clinical assessment parameter. It takes into account pain, limb function, active shoulder elevation in the frontal plane, degree of muscle strength and the patient's satisfaction. The result is expressed as a number of points, with a maximum of 35 points. The SF-36 is a questionnaire containing 36 questions that evaluate quality of life. The raw scale of pain consists of a subjective analysis of the patient's pain, by means of a scale graded from zero to ten, such that zero represents absence of pain and ten represents the worst possible situation. All the patients operated were evaluated before and after the surgery by the same orthopedic surgeon.

Patients over the age of 18 years who signed a free and informed consent statement were included. The exclusion criteria were previous fractures, associated pathological conditions in this region, previous surgery on the affected arm and psychiatric morbidities or neurological sequelae. This study was approved by the institution's ethics committee, under protocol number 0173/10.

All the patients underwent electroneuromyography before the operation and refused to do the same examination after the operation.

\section{METHODS}

In all cases, a procedure to release the SSN trapped in the scapular incisure against the transverse ligament of the scapula was performed.

The patients were subjected to general anesthesia, with blockage of the brachial plexus by means of electrostimulation. They were put into the deckchair position with the backrest at an elevation of $60^{\circ}$ in relation to the floor, and the affected arm was kept flexed, without traction. A standard arthroscope with a $30^{\circ}$ angle was placed in the lateral portal, and bursectomy was performed using a shaver inserted into the posterior portal, until the coracoid-clavicular ligaments could be seen. Radiofrequency instruments were preferred for ablating the points that presented bleeding, because of 
the proximity of vascular and nerve structures. Electrocautery was avoided because of the high temperatures developed and the possibility of nerve injury.

The shaver was then placed in the Neviaser por$\operatorname{tal}^{(9)}$, and the bursectomy was continued, following along the posteromedial portion of the coracoid-clavicular ligaments. Accessory portals can be constructed just above the spine of the scapula with the aid of a jelco 14 catheter, in order to ascertain the exact entry point, thus making it possible to introduce further instruments for cutting the ligament.

The suprascapular artery can be viewed at this moment, medially to the origin of the conoid in the coracoid (Figure 1). The transverse ligament of the scapula is located just below it and at the base of the medial edge of the coracoid-clavicular ligament complex, i.e. specifically, at the edge of the conoid. This technique does not allow adequate differentiation between the conoid and trapezoid ligaments, and they were treated as a single complex in this study.

Bleeding occurs routinely in this space, and great care needs to be taken to avoid injuring or cauterizing the suprascapular artery.

A basket was used to resect the transverse scapular ligament through the portal located above the spine of the scapula (Figure 2), and bleeding at this moment was not unusual. With the aid of a protector for the nerve and artery, the stumps of the ligament could be removed using a basket or shaver, thereby completely releasing the nerve (Figure 3 ).

After the operation, the patients used an arm sling for 14 days, and were then released for active movement in accordance with their pain thresholds.

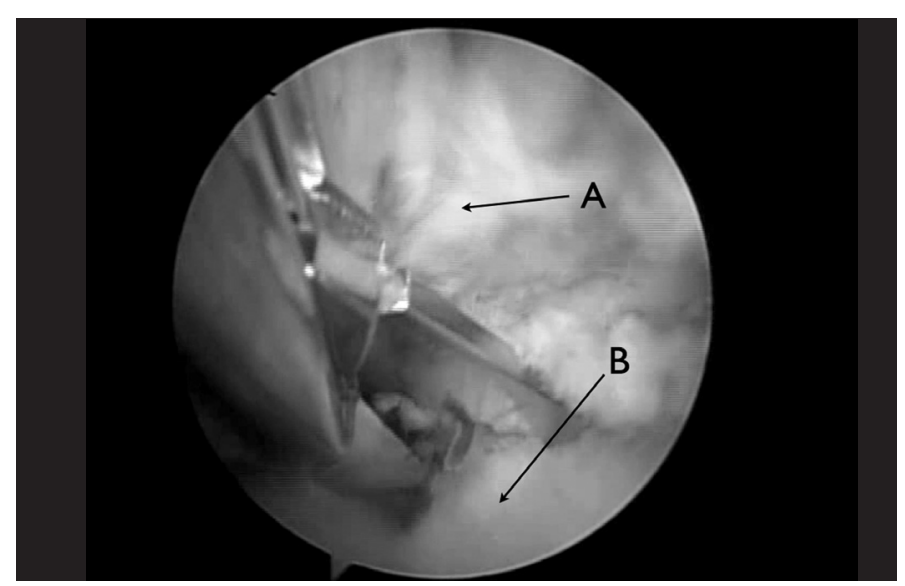

Figure 1 - A) Suprascapular artery; (B) Transverse ligament of the scapula.

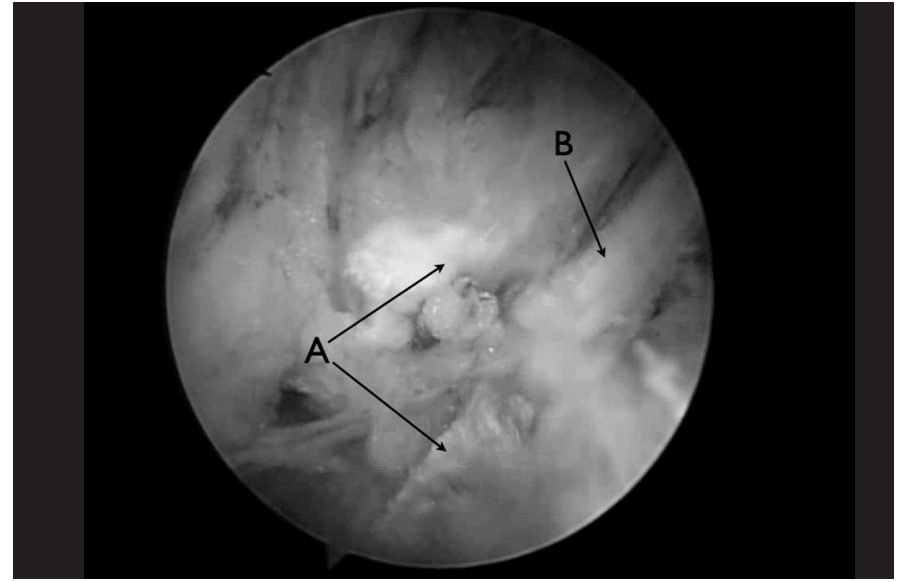

Figure 2 - A) Parts of the transverse ligament of the scapula; (B) Suprascapular nerve.

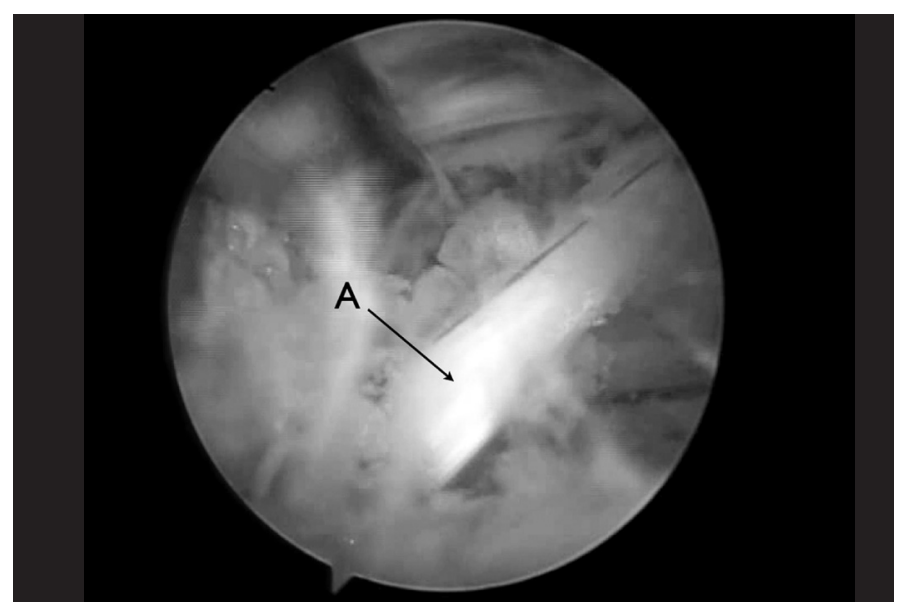

Figure 3 - Released suprascapular nerve.

\section{RESULTS}

Ten shoulders were operated in nine patients: nine shoulders in women and one in a man, of which eight were right shoulders and two were left shoulders. The patients' mean age was 69.5 years (range: $58-80$ years) and mean length of follow-up was 16.6 months (range: 9 - 25 months).

There were no complications relating to nerve injuries, bleeding or infection in this series. All the patients presented alleviated pain after SSN decompression, although in one patient the improvement was not very much. The mean preoperative UCLA score was 11.7 points (range: 8 - 22 points) and the score six months after the operation was 26.1 points (range: 14 - 33 points). The values obtained using the raw scale of pain before and after the operation were compared and are presented in Table 1 in the form of the patients' percentage clinical improvement. This showed 
that there was an improvement of $88 \%$ in the clinical complaints presented (range: $80-100 \%$ ). The SF-36 questionnaire applied after the operation showed a mean score of 122.9 (range: 107 - 142) (Table 1).

In analyzing the type of scapular incisure, it was observed that eight patients presented Natsis type III; one patient, type IV; and one patient, type $\mathrm{II}^{(10)}$.

Table 1 - Pre and postoperative evaluation.

\begin{tabular}{c|c|c|c|c|c|c|c|c}
\hline Patient & Age & Sex & $\begin{array}{c}\text { Length of } \\
\text { follow-up } \\
\text { (months) }\end{array}$ & Side & $\begin{array}{c}\text { Pre-op } \\
\text { UCLA }\end{array}$ & $\begin{array}{c}\text { Post- } \\
\text { op } \\
\text { UCLA }\end{array}$ & $\begin{array}{c}\text { RSP } \\
\text { (\%) }\end{array}$ & $\begin{array}{c}\text { Post- } \\
\text { op } \\
\text { SF-36 }\end{array}$ \\
\hline $1 \mathrm{R}$ & 80 & $\mathrm{~F}$ & 22 & $\mathrm{R}$ & 8 & 19 & 80 & 107 \\
\hline $1 \mathrm{~L}$ & 80 & $\mathrm{~F}$ & 21 & $\mathrm{~L}$ & 8 & 18 & 80 & 107 \\
\hline 2 & 58 & $\mathrm{~F}$ & 20 & $\mathrm{R}$ & 19 & 33 & 95 & 142 \\
\hline 3 & 62 & $\mathrm{~F}$ & 19 & $\mathrm{R}$ & 22 & 30 & 80 & 137 \\
\hline 4 & 61 & $\mathrm{~F}$ & 12 & $\mathrm{R}$ & 13 & 28 & 80 & 136 \\
\hline 5 & 65 & $\mathrm{M}$ & 12 & $\mathrm{R}$ & 12 & 31 & 100 & 135 \\
\hline 6 & 77 & $\mathrm{~F}$ & 9 & $\mathrm{~L}$ & 7 & 31 & 100 & 112 \\
\hline 7 & 69 & $\mathrm{~F}$ & 8 & $\mathrm{R}$ & 12 & 14 & 80 & 110 \\
\hline 8 & 79 & $\mathrm{~F}$ & 7 & $\mathrm{R}$ & 8 & 31 & 90 & 113 \\
\hline 9 & 64 & $\mathrm{~F}$ & 6 & $\mathrm{R}$ & 10 & 26 & 95 & 130 \\
\hline Means & 69.5 & & 13.8 & & 11.9 & 26.1 & 88 & 122.9 \\
\hline
\end{tabular}

Legends: RSP - raw scale of pain; $1 \mathrm{R}$ - right shoulder of patient 1; 1L - left shoulder of patient 1 .

\section{DISCUSSION}

Pathological conditions due to SSN compression have been recognized as potential causes of shoulder pain $^{(11-21)}$. In planning the best treatment possible for SSN compression, it is fundamental to have knowledge of its anatomy and pathology ${ }^{(22)}$. The SSN originates from the superior brachial plexus as a sensory-motor nerve, close to Erb's point and passing below the transverse ligament in the scapular incisure. Two motor branches originate from this point, going to the supraspinatus muscle. Before innervating the supraspinatus and infraspinatus, it takes a deep path to the trapezius and omohyoid muscles and then follows the suprascapular artery to the incisure. The artery passes superiorly to the transverse ligament, while the nerve passes inferiorly to it, into the supraspinatus fossa.

SSN decompression by means of an open procedure is safe and reproducible ${ }^{(9,15)}$. Arthroscopic procedures in this region are difficult because of poor viewing of the area and the anatomical complexity. However, several authors have used arthroscopic techniques for this purpose $\mathrm{e}^{(23-25)}$.
The technique described here differs from the others through its use of a standard arthroscope with a $30^{\circ}$ optic, instead of the $70^{\circ}$ device that is commonly used, because the latter is not routinely available in Brazil $^{(22-24)}$. Furthermore, in the technique described here, traction on the operated limb is not necessary, which makes the procedure less traumatic.

The first anatomical reference point is the acromioclavicular joint. The second is the conoid ligament, close to the suprascapular artery. These parameters guide the arthroscope to the coracoid process and the transverse ligament of the scapula.

Use of a calibrated probe and a shaver as dissection guides in the region of the coracoid-clavicular ligaments is recommended.

According to Mallon et $\mathrm{al}^{(3)}$, Lafosse et $\mathrm{al}^{(22)}$ and

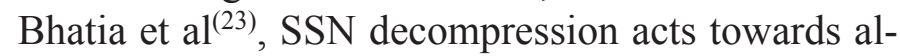
leviating pain in rotator cuff injuries.

In 2007, Natsis et $\mathrm{al}^{(10)}$ proposed a classification for types of suprascapular incisure, after evaluating 423 scapulas from cadavers, consisting of five types (Figure 4). A narrow scapular incisure in combination with an anomalous transverse ligament causes sufficient constriction to be considered a risk factor for SSN compression.

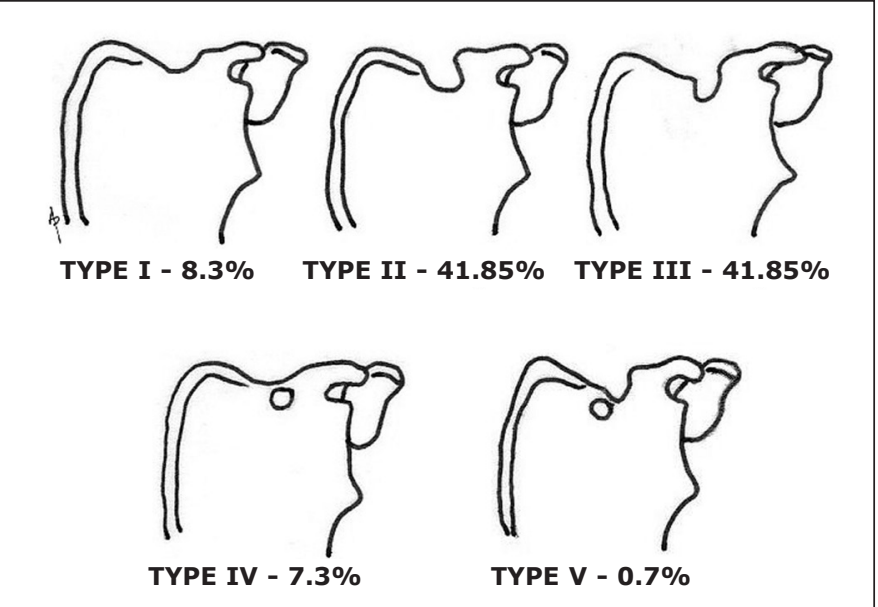

Figure 4 - Natsis classification for the anatomical type of scapular incisure. Type I - without incisure; Type II - greater transverse diameter; Type III - greater vertical diameter; Type IV - bone foramen; Type $\mathrm{V}$ - incisure plus bone foramen.

In analyzing the results from the pre and postoperative evaluations, we observed that there was a satisfactory response on the raw scale of pain, with clinical improvement among the patients. Although the postoperative mean UCLA score did not reach the desired 
level of 27 points, there was a significant improvement in relation to the preoperative situation, given that these patients had presented severe functional impairment. One patient only improved by two grades in the UCLA score, and this can possibly be explained by the type of scapular incisure (Natsis type II). It is therefore suggested that the surgical procedure proposed here might not have a beneficial effect for this type and would be more indicated for the other types.

\section{CONCLUSION}

In cases of irreparable injury of the rotator cuff, decompression of the SSN was shown to be a possibility for improving the painful condition and may constitute a further therapeutic resource, in association with tenotomy or tenodesis of the biceps, excision of the distal clavicle and bursectomy of the shoulder. Patients presenting Natsis scapular incisures of types III and IV are the ones who benefit most from this technique.

This procedure can also be indicated separately in cases of SSN compression due to other causes.

The authors conclude that this condition can be treated safely and efficiently using the technique described here. Knowledge of arthroscopic anatomy is essential for obtaining the best results.

\section{REFERENCES}

1. Thompson WA, Kopell HP. Peripheral entrapment neuropathies of the upper extremity. N Engl J Med. 1959;260(25):1261-5.

2. Garcia JC. Arthroscopic decompression of the suprascapular nerve: surgical technique. Techn Shoulder Elbow Surg. 2009;10(4):157-9.

3. Mallon WJ, Wilson RJ, Basamania CJ. The association of suprascapular neuropathy with massive rotator cuff tears: a preliminary report. J Shoulder Elbow Surg. 2006;15(4):395-8.

4. Post M, Mayer J. Suprascapular nerve entrapment. Diagnosis and treatment. Clin Orthop Relat Res. 1987;(223):126-36.

5. Wood VE, Marchinski L. Congenital anomalies of the shoulder. In: Rockwood CA, Matsen FA, editors. The shoulder. 2nd ed. Philadelphia: WB Saunders; 1998. p. 99-163.

6. Amstutz HC, Sew Hoy AL, Clarke IC. UCLA anatomic total shoulder arthroplasty. Clin Orthop Relat Res. 1981;(155):7-20

7. Ciconelli RM, Ferraz MB, Santos W, Meinão I, Marina RQ. Tradução para a língua portuguesa e validação do questionário genérico de avaliação de qualidade de vida "medical outcomes study 36 - item short - form health survey (SF-36). Rev Bras Reumatol. 1999;39(3):143-50.

8. Acute pain management: operative or medical procedures and trauma, clinical practice guideline No. 1. AHCPR Publication No. 92-0032; Feb 1992. Agency for Heathcare Research and Quality, Rockville, MD; 116-117.

9. Neviaser TJ, Ain BR, Neviaser RJ. Suprascapular nerve denervation secondary to attenuation by a ganglionic cyst. J Bone Joint Surg Am. 1986;68(4):627-8.

10. Natsis K, Totlis T, Tsikaras P, Appell HJ, Skandalakis P, Koebke J. Proposal for classification of the suprascapular notch: a study on 423 dried scapulas. Clin Anat. 2007;20(2):135-9.

11. Pecina M. Who really first described and explained the suprascapular nerve entrapment syndrome? J Bone Joint Surg Am. 2001;83-A(8):1273-4.

12. Alon M, Weiss S, Fishel B, Dekel S. Bilateral suprascapular nerve entrapment syndrome due to an anomalous transverse scapular ligament. Clin Orthop Relat Res.1988;(234):31-3.

13. Ganzhorn RW, Hocker JT, Horowitz M, Switzer HE. Suprascapular-nerve entrapment. J Bone Joint Surg Am. 1981;63(3):492-4.
14. Hirayama T, Takemitsu Y. Compression of the suprascapular nerve by a ganglion at the suprascapular notch. Clin Orthop Relat Res. 1981;(155):95-6.

15. Ogino T, Minami A, Kato H, Hara R, Suzuki K. Entrapment neuropathy of the suprascapular nerve by a ganglion. A report of three cases. J Bone Joint Surg Am. 1991;73(1):141-7.

16. Rengachary SS, Burr D, Lucas S, Brackett CE. Suprascapular entrapment neuropathy: a clinical, anatomical, and comparative study. Part 3: comparative study. Neurosurgery. 1979;5(4):452-5.

17. Ticker JB, Djurasovic M, Strauch RJ, April EW, Pollock RG, Flatow EL, Bigliani LU. The incidence of ganglion cysts and other variations in anatomy along the course of the suprascapular nerve. J Shoulder Elbow Surg. 1998;7(5):472-8.

18. Mcllveen SJ, Duralde XA, D'Alessandro DF, Bigliani LU. Isolated nerve injuries about the shoulder. Clin Orthop Relat Res. 1994;(306):54-63.

19. Yoon TN, Grabois M, Guillen M. Suprascapular nerve injury following trauma to the shoulder. J Trauma. 1981;21(8):652-5.

20. Asami A, Sonohata M, Morisawa K. Bilateral suprascapular nerve entrapment syndrome associated with rotator cuff tear. J Shoulder Elbow Surg. 2000;9(1):70-2.

21. Warner JP, Krushell RJ, Masquelet A, Gerber C. Anatomy and relationships of the suprascapular nerve: anatomical constraints to mobilization of the supraspinatus and infraspinatus muscles in the management of massive rotator-cuff tears. J Bone Joint Surg Am. 1992;74(1):36-45.

22. Lafosse L, Tomasi A, Corbett S, Baier G, Willems K, Gobezie R. Arthroscopic release of suprascapular nerve entrapment at the suprascapular notch: technique and preliminary results. Arthroscopy. 2007;23(1):34-42.

23. Bhatia DN, de Beer JF, van Rooyen KS, du Toit DF. Arthroscopic suprascapular nerve decompression at the suprascapular notch. Arthroscopy. 2006;22(9):1009-13.

24. Barwood SA, Burkhart SS, Lo IK. Arthroscopic suprascapular nerve release at the suprascapular notch in a cadaveric model: an anatomic approach. Arthroscopy. 2007;23(2):221-5. 